This item was submitted to Loughborough's Research Repository by the author.

Items in Figshare are protected by copyright, with all rights reserved, unless otherwise indicated.

\title{
'Put that in your fucking research': reflexivity, ethnography and disability sport coaching
}

\author{
PLEASE CITE THE PUBLISHED VERSION
}

https://doi.org/10.1177/1468794120931349

PUBLISHER

SAGE Publications

VERSION

AM (Accepted Manuscript)

\section{PUBLISHER STATEMENT}

This paper was accepted for publication in the journal Qualitative Research and the definitive published version is available at https://doi.org/10.1177/1468794120931349 Users who receive access to an article through a repository are reminded that the article is protected by copyright and reuse is restricted to noncommercial and no derivative uses. Users may also download and save a local copy of an article accessed in an institutional repository for the user's personal reference.

\section{LICENCE}

All Rights Reserved

\section{REPOSITORY RECORD}

Townsend, Robert C, and Christopher Cushion. 2020. "'put That in Your Fucking Research': Reflexivity, Ethnography and Disability Sport Coaching”. Loughborough University.

https://hdl.handle.net/2134/12464702.v1. 
"Put that in your fucking research": Reflexivity, ethnography and disability sport coaching.

Robert C. Townsend ${ }^{\mathrm{a}}$

Christopher J. Cushion ${ }^{\mathrm{b}}$

${ }^{a}$ Te Huataki Waiora School of Health, Sport and Human Performance, University of

Waikato, New Zealand. robert.townsend@waikato.ac.nz

10

11

${ }^{\mathrm{b}}$ School of Sport, Exercise and Health Sciences, Loughborough University, UK, c.cushion@1boro.ac.uk

13

14

15

16

17

18

19

20

21

22

23

24

25

26

27

28

29

30

31

32

33

34

35

36

37

38

39

40

41

42

43

44

45

46

47

48

49

50

Corresponding author: Robert Townsend, robert.townsend@waikato.ac.nz 


\section{Abstract}

52 Reflexivity is continually called for as a marker of quality ethnographic research. In this paper 53 we put reflexivity to 'work', providing a critical commentary on data generated through 54 ethnographic fieldwork in high-performance disability sport. Drawing on Bourdieu's reflexive 55 sociology, we situate the ethnographer in the field of disability sport, turning a reflexive lens 56 onto the practices that are associated with occupying the role of coach and researcher

57 simultaneously. We illustrate the centrality of researcher subjectivity - through the reflexive device of 'crossing fields' - as a productive resource for examining the social and intellectual unconscious embedded in the process of doing ethnographic research. In so doing, we provide

60 a unique example of how reflexive practice can offer a rigorous, power-conscious reading of 61 an ethnography of high-performance coaching in disability sport.

62 Key words: ethnography; reflexivity; disability; disability sport; coaching

63 Word count: 7975

64

65

66

67

68

69 
Reflexivity is firmly embedded within the language of social science and is well-established as a critical component of qualitative research. The reflexive turn has a long history, embedded in earlier critiques of epistemology, methodology and representation in social science (see Clifford and Marcus, 1986; Geertz, 1987; Denzin and Lincoln, 2011). Reflexivity itself, however, is a difficult concept to put to 'work', and can be subject to a good deal of conceptual slippage. There are different interpretations, approaches and positions for researchers to make sense of and operationalise (Foley, 2002), suggesting that, as Olive and Thorpe (2011) claim, reflexivity is increasingly "under-defined, and hollow" (p. 424).

It might be reasonably argued that despite ongoing recourse to reflexive practice, reflexivity constitutes a taken-for-granted or uncritically-accepted term (Maton, 2003) in which to be reflexive is taken as a proxy for individualistic self-reflexivity, either through autoethnographic or confessional tales (Van Maanen 1988; Sparkes, 2002). This refers to the ways in which the researcher writes themselves and their backgrounds into the text or analysis in order to demonstrate how their social history and identity influence their interpretations (e.g. Berger, 2015). These analyses are valuable for explaining 'hidden insight' into phenomena through either personal connections or lived experience, or for reflecting on the social problems that ethnographers have to 'grapple' with, such as negotiating power relations, ethical dilemmas, voice, subjectivity and interpretation (Sparkes, 2020).

Self-reflexive analysis, naturally, places emphasis on the agency of the researcher.

92 However, this 'ethnocentric' position is not without its criticisms (see Wacquant, 1989;

93 Bourdieu and Wacquant, 1992). Indeed, such approaches have been dismissed as a "selfindulgent discussion about ethnographers between ethnographers" (Gibson and Atkinson, 2018: 446; Wacquant, 1989) that, at worst, provides a platform for tedious, benign and 
relativism or regressive self-analysis, thus bringing the ethnographic enterprise to "a grinding halt" and leading to the rather disheartening conclusion that "all is in the final analysis nothing but discourse" (Bourdieu, 2003, 282).

In direct contrast to this form of reflexivity is the more 'objective' reflexivity of Pierre Bourdieu. A key component of Bourdieu's sociological method was the "methodical reflection on the act of objectivation itself' (Wacquant, 2004: 389). Bourdieu's particular stance of epistemic reflexivity demands that social scientists interrogate their 'scholastic posture', turning the 'tools of social science' (i.e. theory) on to the researcher themselves and the fields in which they are situated (Bourdieu, 2003). For Bourdieu, a truly reflexive sociology must make transparent how ethnographers, situated within the academic field, produce 'truth' claims and facts (Foley, 2002), highlighting the social and intellectual conditions that shape research practice. Reflexivity, thus, represents "the permanent sociological analysis and control of sociological practice" (Bourdieu \& Wacquant, 1992: 40). Bourdieu's reflexive practice might therefore be understood as both methodological and theoretical; recognising how engaging in research shapes, and is shaped by, the situated aspects of the researchers' social selves and the “invisible determinations" inherent in the scholarly gaze (Wacquant, 1989: 34).

Such is the strength and value of reflexivity that it is routinely called for in ethnographic research broadly (Alvesson and Skoldberg, 2009; Van Maanen, 1988). This necessity for reflexive practice is magnified in areas of research that demand reflexive self-scrutiny and the careful theorising of claims made (Howe, 2009). Following this, our specific use of reflexivity is anchored in the context of coaching in disability sport. Berger (2015) recently argued that it is important to deepen our understanding of reflexivity across diverse contexts. Indeed, disability sport is a social institution that has considerable sociological significance, providing a lens to consider the grounded, historical and everyday discourses and practices that perpetuate social differentiation and accentuate the social categories of disability and disabled people. 
123 illustrated the ways in which sport acts as a complex site of empowerment for disabled athletes.

124 In disability sport, disabled people are able to negotiate an affirmative disability identity 125 associated with an 'athlete-first' discourse (see Berger, 2008; Powis 2018). Focusing 126 specifically on coaches and coaching provides critical insight into the constructed patterns of 127 social reality that constitute disability sport (cf. Alvesson and Skoldberg, 2009). Coaches are central figures in maintaining such discourses and coaching itself is a set of social practices that are produced as a response to these situated understandings of disability. Recent research

130 has illustrated that the pedagogic function of coaching reproduces rather than redistributes 131 unequal social relations, thus imposing 'athlete-first' discourses based on highly-regulated 132 principles of performance, self-government, achievement, challenge and independence, to construct a disabled athlete subject (Author A, B and others, 2018). At the same time, this highperformance sport value system refracts deeper value judgements based on ableism. It is in these complexities and contradictions that frame disability research that this study sits.

\section{Crossing Fields}

137 In this paper we operationalise Bourdieu's reflexive stance through the notion of 'crossing 138 fields' (cf. Thorpe, Barbour and Bruce, 2011; Olive and Thorpe, 2011). Fields are social spaces that are defined as a "network, or a configuration, of objective relations between positions"

140 (Bourdieu \& Wacquant, 1992: 97). Crossing fields as a reflexive device illustrates how the first

141 author was deeply embedded in the local relationships, politics and ideologies of a distinctive 142 disability sport context, as well as the disciplinary specialty. Crossing fields therefore brings to the forefront the way I (first author) moved between my field experience and the abstract

144 theoretical explanations of that experience. In doing so, we attempt to provide a practical and 145 theoretical grasp of the social conditions of 'doing' fieldwork, and a close scrutiny and mutual 146 questioning of the very production and interpretation of field data (Wacquant, 2004). 
In putting the idea of crossing fields to work, we emphasise the "destabilizing and

148 potentially subversive effects that might arise from movement across fields" (McNay, 1999:

149 107), suggesting that moments of misalignment and tension between habitus and field may

150 give rise to increased reflexive awareness (Bourdieu and Wacquant,1992). It is in these

151 moments of tension that habitus forces a degree of "negotiation with itself and its

152 ambivalences" (Thorpe, 2009: 503). This process of introspection when engaging in fieldwork

153 can be productive, acknowledging the social rooting and split subjectivity of the ethnographer

154 "without reducing ethnography to the rhapsodic evocation of subjectivity" (Wacquant, 2004:

$155398)$.

156 Aims and Purpose

157 Despite extensive debate and discussion about the importance of reflexive practice to social science research, there is a lack of research actively putting reflexivity to 'work' (Berger, 2015). As a result, there is little guidance for researchers wishing to provide grounded and

160 reflexive accounts of the research process. Consequently, the aim of this paper is to 161 demonstrate how Bourdieu's reflexive framework acted as a theoretical resource to enable 162 heightened awareness of the sensitivities of 'doing' research in a social site that is routinely described as 'non-disabling' and 'empowering', yet is constructed according to ableist values and practices (Author A, B and others, 2018; DePauw, 1997; Powis, 2018). Our specific reading and use of reflexivity, however, should not be seen as the way, rather we hope to

166 illustrate a way in which sport coaching research can offer a level of criticality and rigorous

167 self-awareness that has relevance for social science researchers more broadly. Our (somewhat overdue) turn to reflexivity is not a call for naval-gazing. Sharing these insights has the potential to bring into sharper focus perhaps the most consuming issue faced

170 by ethnographers: that of accessing, negotiating and representing socially-significant patterns 171 of culture. The second, and related, purpose of this research then, is to provide a level of 
ethnographic authenticity to representations of social reality. We do this not through 'truth "within and between academic and research fields - or put another way, between theory, practice and culture" (Olive \& Thorpe, 2011: 430).

\section{Fieldwork context}

177 In the following sections, I (first author) present my experiences as a researcher and a coach embedded within a high-performance disability sport coaching context. At the outset it is important to acknowledge that my position as a non-disabled researcher and coach is a

180 significant factor in the production of this research ${ }^{1}$ (Oliver, 1992). In this process of presenting my experiences, I necessarily abstract them, but do so in order to detail the tensions, processes and conflicts comprising the fieldwork. Doing so may provide a shared language and conceptual framework for researchers undertaking ethnographic research in highly stratified disability contexts.

The experiences presented below were produced through eighteen months of fieldwork with a national learning disability sports team. My role as observer in the ethnographic study for this research was formulated entirely through my experiences as a member of the coaching staff, working closely with both the staff and the players ${ }^{2}$. My participation was more or less complete physical, social and psychological involvement within the coaching culture throughout training and competition cycles. This immersion enabled the representation of the

\footnotetext{
${ }^{1}$ Although my focus was on coaching practice and not the disability experience, there is still a degree of cultural sensitivity and nuance required in the claims made about practice and it was not our intention to provide a reflexive standpoint ethnography (see Howe, 2009).

${ }^{2}$ Given the unique coaching context, discussions of confidentiality were had with participants at the outset of the research as a means of obtaining informed consent. It was explained that all possible precautions will be taken to disguise individuals' identities in the data. Anonymity proves a problem, however, as Kaiser (2009) notes, removing all of the identifying characteristics from the research (i.e. learning disability), would inhibit our ability to convey the lessons learned from this particular study. These choices are confronting in every aspect of 'writing up' the research.
} 
routine, everyday action of the participants over time. In so doing, I occupied a complex position in that I was simultaneously a part of the object of study, both participating and observing. Throughout the fieldwork process I kept detailed field notes of the day-to-day

194 workings of the training camps and competitive fixtures. These included, but were not limited to, the interactions between players and staff at various points, such as evening meals and time spent in hotel bars, spas and the gym, as well as the dedicated practice sessions or in the changing room during a competitive fixture. What follows are my reflexive analyses of some of the more difficult situations that arose as I worked through the research process.

\section{"Full of spiel, mate": Power and Respect}

200 My integration into the team environment was swift. The players, for the most part, were 201 familiar with me, and the coaching staff welcoming. Like most elite sport environments, the coaching staff ${ }^{3}$ of the learning disability squad was structured along hierarchical lines, with the Performance Director responsible for the overall strategic and financial direction of the squad.

The head coach oversaw the contributions of the individual members of the management staff and the technical, tactical and social direction of the team, and in particular expressed an interest in my research topic. This meant that my cultural capital in the form of educational qualifications, combined with a pre-existing understanding of the conventions of the field were crucial in enabling a position on the coaching staff, positioning me in a legitimate social position that guaranteed both entry and access (cf. Ball, 1990).

211 closely with the players on a day-to-day basis, where I occupied a supporting role, highlighting

212 the often natural and embedded hierarchies of coaching. We would often travel to training

\footnotetext{
${ }^{3}$ Alongside the coaches, the team manager was responsible for organisational and administrative duties for the team and the coaching staff. However, during the period of fieldwork a financial commitment from the governing body meant that the team manager was able to take on an additional part-time role as Personal Development and Welfare Officer (PDW). The rest of the management staff was comprised of a physio, a parttime nutritionist and a strength and conditioning coach.
} 
213 camps together, forming a tight relationship and engaging in many 'off-the-record'

214 conversations ${ }^{4}$. I would actively spend time with him, spending evenings with him in the bar

215 and travelling with him to games. In doing so I had to negotiate my continually shifting role as

216 participant and researcher, where, despite his public scorn of academia ("academics are just

217 full of spiel mate - overcomplicating simple things" - field notes), and prolonged 'banter'

218 toward my research, in private he was thoughtful and would regularly probe my views on

219 coaching.

220 It was common for the coaching and management staff to give their opinions on players

221 and discuss confidential information in my presence whether in the training hall or in the hotel

222 bar. Issues continually arose, for instance, about players' sexualities, medication and

223 impairment effects, their (sometimes volatile) home lives or concerns about lifestyle and

224 behaviour, despite knowing that I was actively conducting research on the topic. Inevitably my

225 positioning within this subculture was more complex than 'insider' status indicates. While I

226 actively sought to declare affinity between myself and the participants and to distance myself

227 from constraining identities (Hammersley \& Atkinson, 2007), to do so I was drawing on my

228 bodily resources, my maleness, my able-bodiedness (and with it my athletic ability) to position

229 myself in simultaneous competing roles as both researcher and coach. Here, blurring the lines

230 between fields was both necessary and beneficial in gaining entry to the research site in a

231 position of power, i.e. as a member of the coaching staff, but to provide access I had to actively

232 disassociate from the role of 'researcher'. Despite this, the fact that I was a researcher was

233 never forgotten completely:

During one particular morning of training, the assistant coach and I had set out a number of activities across the sports hall.

236

237

"Okay, lads, you know what to do. Off you go" the coach barked.

\footnotetext{
${ }^{4}$ While some might conceptualise this as cultivating a 'key informant', I reject this as it invokes a level of strategy and cunningness to an otherwise naturally unfolding social relationship. Of course, our relationship helped me to navigate the power dynamics of the context and learn my 'role' in the field.
} 
The players turned and made their way sluggishly to the 'stations' spread around the hall. A minute passed and they were still not in position. The assistant coach swore under his breath and shouted for the players to gather around him. He addressed them angrily.

“Lads, LD or not, when I say, 'off you go', what do you do?"

There was a painful pause. One of the players eventually piped up "off we go?"

"Fucking right!" He looked at me . "Put that in your fucking research, (author name)!"

(Field notes).

Players would often express an interest in my research, and a keenness to be interviewed. At first, the players' reaction to my wearing a microphone was wary, and it became an object of masculine-dominated humour, as exemplified in the following passage:

$\mathrm{M}$ had been staring at me during the team briefing. I had noticed, and though I tried to encourage him to continue listening, his eyes kept flicking down to my collar, and mouthing silently to me "the fuck's that?"

He grabbed me as the players dispersed into the warm up routine and pointed at my collar: "Oi! Is that thing on?", as he nodded towards my microphone, tucked on the inside of my top. I smiled,

"Yep, everything you say mate. I've got to listen back to it, no swearing though, okay?"

M beamed a smile: "ah" He leaned close and growled, "you're a cunt!" before running off towards the rest of the boys 'whooping' with glee.

(Field notes).

These data give a flavour of the subtle authoritarian, ableist and masculine discourse which housed the coaching environment, wherein I had to actively protect my position as a coach while at the same time conserving my research interests. After this incident I quickly abandoned the microphone to allow the players to get over any sense of curiosity, and stopped bringing my notebook to the training hall. While the fact that I was actively researching the squad was recognised as part of a wider process of professionalisation and high-performance in disability sport I actively sought to minimise my 'otherness' and maximise my associations to the rest of the coaching staff: 
For me it's a performance environment now. It wasn't four years ago. I think...we've got better backroom staff, more professional backroom staff. I think by having people of that calibre around it automatically ups the game, and I think the players have responded to that. We're very different people (which) is to me the biggest thing. We've got one and a half doctors (laughs) but when you get your letters at the end of your name then we're going to have potentially two doctors involved in the squad. We've got a highly experienced level four coach; we've got a former pro. We've got a physio who works for first-class county. We've got a nutritionist who is also a teacher. So having not only a massive personality shift across the board but also actually everyone is pretty much kind of at the top of their game in terms of qualification, and that's made a big difference as well. (Team Manager - interview).

I think where we're at as a management team at the minute is probably as strong as I've ever felt it. Yeah there's a high calibre of education, I think a high calibre of people is a different thing, but I think this group combine that education and personal attribute well. (Head Coach - interview).

In negotiating the fieldwork setting the underlying processes of micro-access were continually constrained and enabled by the exchange and recognition of cultural capital. Cultural capital is useful in illustrating the micro-interactional processes through which individuals are judged according to cultural frameworks of evaluation and distinction. For example, though educational qualifications had social currency within the environment, a mark of distinction exists in coaching for those that have played at a professional level (Blackett et al., 2015), such as the assistant coach:

I think straightaway there's an instant respect. There's a respect I think from the start that these lads, you know, and I'm still playing now, which is nice, and I think that there's a respect as a player. From what I've been involved with and what I've done as a player, obviously not, nowhere near as high as a lot of players, but I'd like to think that I've certainly done enough as a player to warrant a place in the performance environment, I think. (Assistant coach, interview).

The 'technical' skills and knowledge regarding 'the game' are a highly valued aspect of coaching (Author A and B, 2015; Blackett et al., 2015), which are "the product of an investment of time and cultural capital" (Bourdieu, 1986: 244). For researchers, there are unavoidable implications. For example, sometimes the fieldworker may find her or himself being 'tested', and it is not uncommon for new members within the group to effectively have to 'prove their worth' or gain acceptance (Hammersley \& Atkinson, 2007). In my case, during 
my first 'official' training camp, I was challenged to a target throwing competition by the

311 assistant coach in front of the players. I was expected to demonstrate the technical skills the

312 players had been working on and execute the throw towards a target around twenty metres

313 away. As the players gathered around, failure would have undoubtedly resulted in good-natured

314 ridicule and 'banter', and perhaps more insidiously, undermined my credibility as a coach.

315 While I was taken aback, I executed the throw well and hit the target to the cheers of the players (and indeed to my own delight). The assistant coach was then left with the task of maintaining face with the players by completing the 'challenge' himself. Afterwards, banter aside, he explained that "the boys love that sort of thing, you have to be able to do it y'know? To get their respect" (field notes). In this sense, technical competence was a strategic resource by which I was able to secure my position within a status hierarchy (cf. Lareau \& Weininger, 2003). Engaging in these strategies for the "appropriation of symbolic wealth" (Lareau \& was advantageous. Bourdieu (1996: 119) suggested that these displays of competence are highly gendered, and have both a technical dimension and a status dimension, arising as actors pursue different interests:

"dominants always tend to impose the skills they have mastered as necessary and legitimate and to include in their definition of excellence the practices at which they excel".

The implications for ethnographers are clear in terms of considering the social relations that

330 structure their chosen sites of research, and the social resources held that impact on the possibilities of data collection. In other words, the history and proximity of the power relations in the field make it possible (or not) to structure workable research relations, and grant the access to be able to construct meaningful data. Though I began this work as a relatively

334 inexperienced coach in the disability sport context, I had 'institutionalised' cultural capital 335 (Bourdieu, 1986) in the form of 'mainstream' coaching experience, knowledge and academic 
qualifications guaranteeing a level of technical capacity and social competence to access the players $^{6}$, and certainly my maleness contributed to my acceptance into a male-dominated coaching culture. However, as the research developed I became increasingly aware of the various forms of power operating through an entrenched coaching culture and the subtle strategies members of the coaching staff would employ to negotiate space within the hierarchy:

The strength and conditioning coach and I had gone for a walk around the pitch during one of the games. As we discussed working with the team, he asked me for feedback on his coaching. At first, I was reluctant -

"I know very little about strength and conditioning, mate"

"No, fuck that - you know coaching". We clapped in support of one of our players.

I paused as I thought how best to reply. "Okay well, you know your stuff. I think sometimes you use pretty complex or technical language with the players, I mean, it would throw me off, but you compensate that with clear demonstrations".

"Yeah that's important with these boys. You're right though I just can't help it sometimes. I've got to the point now where I just don't give a shit anymore".

As we completed our lap we reached the rest of the coaching staff who were sat by the changing rooms.

"Oh, here they are look, bet that was an interesting chat" the assistant coach chirped. The physio chuckled.

I faked a laugh, "actually, mate, we were discussing coaching, funny how you never ask me for feedback on your coaching?" I smirked. The head coach turned to his assistant with his eyebrows raised.

“yeah, it's because I don't respect you as a coach!” the assistant coach laughed.

\footnotetext{
${ }^{5}$ For a further explication of the assumed relationship between high levels of playing competence and coaching expertise, see Blackett et al., (2015).

${ }^{6}$ For example, during one of my first training camps, one of the players mistakenly referred to me as a former professional player. I never corrected him.
} 
In this interaction I was inserted into a "struggle for status" (Aune, 2011: 429) - a network of power relations where cultural capital was used as a 'weapon' (expressed as 'banter'), defining the "limits of competence" and therefore the "right to speak" (Bourdieu, 1984: 412). The relationship between the researcher and the field was characterised by the composition and volume of capital each member possessed and the extent to which they recognised similar forms in others. Indeed, Atkinson and Gibson (2017) contend that power is central to understanding the production and distributions of practices and systems of knowing, creating 'social facts' - in this case - assigning symbolic power to certain understandings of coaching disabled athletes. Thus, for Bourdieu capital is central to the process of domination that defines the orthodoxies within the field, that is, the way things were 'done'.

\section{“Let him have it"-(Re)producing the orthodoxy}

Reflecting on my scholastic point of view; the "dispositions, productive of unconscious theses"

(Bourdieu, 1990b: 381) which were acquired through sustained engagement with critical disability studies (e.g. Thomas, 2007) inevitably shifted the emphasis and orientation of my analysis throughout the fieldwork onto the construction of disability. What was immediately observable in the coaching context was a concerted effort to 'leave the disabilities at the door' of the training hall and to reinforce the high-performance nature of the squad. Though the head coach in particular resisted this designation, the practical effect of this was that the coaching staff endeavoured to look beyond the players' 'disability' in the design of practices, skill development, target and goal-setting and lifestyle modification. Together, we as a coaching staff operated according to a shared and implicit framework of disability 'empowerment' that involved high levels of 'challenge' for the athletes. As a result, maintaining and occupying my coaching 'role' required an acceptance of the pre-existent conditions that constituted the field - i.e. a doxic order (Bourdieu, 1977) related to a culturally-specific understanding of disability and the patterns of response embedded in social practice (coaching). 
397 from the urgency of practice - I felt that there were serious limitations to approaches that downplayed the immediacy of impairment. The impairment(s) that an athlete presents has a direct and important influence on the role and function of the coach (cf. Thomas, 2007) particularly in a social world which had been shaped by and was contingent on the players' disabilities. The literature was clear - looking past impairment blurred the lines with ableism of coaching, I embodied the ideologies of 'challenge' and discourses of empowerment that underpinned the coaching process enthusiastically. This analytic act did not sit comfortably. that emphasised "a particular kind of self and body" (Campbell, 2009: 5), that is, practices designed to shift the orientation of the coaching environment towards high-performance. These ideas were seductive, couched in positive rhetoric and encouraging of an 'empowering' view of disability coaching practice. They were 'common sense'. To challenge this focus felt like it was against the 'rules' of the game, or 'disempowering' for the players. Assuming I could articulate and voice concern, I risked alienating myself from the other coaches, providing empty critique. So, while I recognised and problematised some aspects of the coaching process, as Adkins (2003: 36) argued, simply "the habitus will always submit to the field": My directive was to feed the ball quickly, quite short and straight, therefore likely to hit A in the chest, ribs or head. A was expected to "make a decision" to either get out of the way, to defend, or to play an aggressive shot. As we settled into the practice, my 'feeds' gradually became faster until I let him 'have one'. The ball leapt up and thudded into A's ribs. He crumpled almost immediately.

I jogged over to him.

“are you okay, mate?” 
He was on all fours, his back rising and falling quickly as he struggled to control his breathing.

"Sorry mate, I didn't mean to, you know what you did wrong though?"

He didn't speak to me. Just shook his head before getting to his feet.

As I returned to my position, A faced up, and I fed a visibly slower, fuller delivery to which A played a tentative shot.

I looked across the hall at the head coach. He'd seen what had happened. With a grim face, he said:

"Don't let up, don't back off. Let him have it".

The next delivery was faster. A barely moved before it hit the back net, flashing past the grille of his helmet.

Again.

The next delivery. Fast and short. The ball thudded into the back net.

A walked out of the net. As he walked towards me his face showed a grimace of pain. With tears in his eyes he croaked "I'm done". I just nodded.

After, I quietly approached the physio to ask if he had 'taken a look' at A.

"Yes, he came over to me. He said he'd been hit by a ball. End of conversation" He laughed.

(Field notes).

Such was the weight of the high-performance doxa that I consciously facilitated practices designed to encourage 'failure'. This was a performative response to the expectations the coaching environment necessitated and demanded. As coaches we constructed an ongoing discourse of dominant ideas about the 'correct way' of coaching in this context that was reinforced from the top down:

You know I still think we've got, there's still a bit of a patronising culture I think sometimes towards disability and I think some of our coaches have had it when they've come but I think they soon lose it once they start working with the guys and they see the ability. I don't think disabled people want continuously reminding of their disability, they want to be spoken to as (athletes). (Performance Director - Interview). 
In my role as a coach, these discourses had all the appearance of a common-sense response to oppression. In the closeness required for the fieldwork, however, I failed to recognise the highly individualising, ableist (Campbell, 2009) and masculinist coaching gaze that framed these practices. As a coach, working to emphasise the high-performance nature of the team, the coaching staff and I were drawing on a set of co-constructed beliefs and ideas that were linked to a collective (mis)recognition that disability empowerment could be achieved through association with performance-level sport.

However, the social relations that structured these ideas and beliefs were inherently unequal - the dominant group (coaches) imposed a valued identity on the players creating a powerful social framework for the development of collective habitus (Bourdieu, 1977). Such was the power of this coaching approach that the coaches and athletes were oriented towards a singular and common purpose:

Coaching practice today was focusing on playing off the 'back foot' at pace. There were four 'working' nets, each with a bowling machine with a different task to be completed. They were generally presided over by the players who moved between nets in groups of three and four, feeding each other six to twelve balls each before swapping. The assistant coach presided over one net, with me observing, and we worked with a player (J). As I observed the practice, I noticed the level of intensity in this particular net. It involved $J$ repeatedly facing balls out of the machine upwards of $75 \mathrm{mph}$, generally directed towards J's chest, neck and head. J's directive was to "get in a good position".

Time after time the ball flashed past J's head, thudded into his gloves or crunched into his rib cage. More than once $J$ ended up in a heap on the floor, getting to his feet shakily. As this happened, the rest of the players began to watch. As I stood next to the coach, I could see J's face getting redder and redder, his eyes wide, but not backing down. The coach continued to feed the balls into the machine, giving $\mathrm{J}$ little respite as the ball continued to strike him on the pads, into his thigh-pad or whistling past his head. There was a hushed silence from the other players, broken only by loud exclamations from the coach. I could see that the player was in pain and getting anxious and upset, despite not taking a backward step. This practice continued until eventually there were no balls left, and $\mathrm{J}$ walked out of the net in tears.

497 Collectively, we as a coaching staff produced a situated and practical understanding of 498 disability coaching that was "commensurate with the interests of dominant groups (and the 

'empowerment':

It's good for the other players to see a player of his (J's) stature struggle. [It] is a massive message that, hang on here, well J's struggling, I'm allowed to struggle. For me that was a defining moment because it became an acceptance amongst the boys, that actually you know what, we don't have to get it completely right every time, failing occasionally is okay. You know, I'm not going to get things completely right every single time, and to me that was a defining moment, a big statement that, a big statement. (J) was always going to bounce back, he's that sort of lad, he's keen, there's a wider context to it, he's always messaging me, he's looking for reassurance, he wants to improve his game, he wants to be the best he can be, so it wasn't, it was done in the right way. The intention wasn't to upset him. (Assistant coach - interview).

Thus, the framework on which practice was based therefore had all the appearances of an enabling structure that, in the coaching field, made 'practical sense' and was firmly embedded and internalised within the coaching culture through positive discourse and collective acceptance (Silva \& Howe, 2016; Purdue \& Howe, 2012). My sense of unease and disquiet with these practices, however, continued:

J: I will confess last year I had a bit of a shock to the system in terms of how much I'd been challenged in the past although I'd been challenged it was still relatively within my comfort zone.

I: we took you out of your comfort zone.

J: It really did, I will confess as well, I actually broke down in one session and it took me a while to get over it.

(Player focus group).

\section{Ethics, self and a sense of one's place}

As Ball (1990) argued, in ethnography, maintaining the research self "is a deliberate process unlike many other social interactions" (p. 158), requiring careful and sensitive responses to other actors in the field. As such, while a researcher I also had to maintain my identity as a coach whose responsibility towards the players was that of utility and care, and at the same time managing my professional responsibilities towards the institution. At times, however, the 
immediacies of fieldwork were troubling. These are what Guillemin and Gillam (2004) refer to as ethically important moments. For example, one afternoon while observing the players taking part in a fitness session, the strength and conditioning coach described his frustration at

534 the players' lack of physical fitness and remarking to me how "dumb" they are. Though such 535 language is not uncommon in many sporting interactions, considering the context I was 536 immediately confronted with a wave of shock and laughed nervously in response. My complicity and silence, however, were embedded in a relational hierarchy and habitual response to protect my position. Responding critically was not an easy, or - I felt - available, choice to make. In this encounter, I felt that my position in the 'field' was not sufficiently stable that I felt I could challenge this, and, more invidiously, for the purpose of obtaining authentic, 'good' data, discretion was as much a social accomplishment as frankness (Hammersley \& Atkinson, 2007). In reflexive consideration of my role, the unique social dynamics and the immediate politics of academic research, I stood to lose more than I had to gain by resisting the relations of power. My laughter ultimately is an example of what Pillow (2003: 192) argued is a "failure of our language and practices" as researchers, and the guilt of being complicit as an agent of ableism (Campbell, 2009) continues.

Guillemin and Gillam (2004) argue that such situational ethics can be messy and difficult to navigate. Throughout the fieldwork the choices I made, while confronting and uncomfortable, were ethical acts that were reflective of a "sense of one's place" (Bourdieu, 1989: 17). In order to 'maintain my rank' with the coaches, and 'keep my distance' from the players, I displayed the symbolic competencies expected in that role (i.e. a high-performance coach). Furthermore, to add a layer of complexity, on the face of it I agreed - and still do - with the situated and practical ideologies that framed the practices (though not always the practices themselves). Indeed, Bourdieu (1989: 17) suggested that agents who "occupy similar or neighboring positions are placed in similar conditions and subjected to similar conditionings", 
and therefore may consciously or unconsciously acquire similar dispositions (and therefore practices) that imply an adjustment to the position occupied in the field. As I actively participated in social practice I passed through the field, internalized it, and shaped my thoughts and actions in order to profit from it. My failures to confront these seemingly 'natural limits' that shaped my coaching practice - and subsequently my research - meant that I was an accomplice in the reproduction of the doxic order, mainly as it was in my interests to do so.

\section{Crossing Fields, Crossing Back}

563 This paper is anchored in what Ball (1990) described as the 'self-doubt and distrust' of my 564 ongoing analyses. What followed was an attempt to highlight my relation to my object of study 565 (Wacquant, 1989). Crossing fields as a reflexive device provided access to the 'blind spots' 566 structured by doxic acceptance of the conditions of the field - that were immediately unobservable. The use of a reflexive method therefore illustrated the "difference between practical knowledge and scholarly knowledge" (Bourdieu, 1988: 1), and particularly the difficulties involved in breaking with 'inside experience'.

It was at times easy to forget the gap that separated the interest that I had in coaching as a researcher who set out to understand and to collect 'good' data, and the practical interest I had in conserving this same system as an ambitious, keen coach (cf. Bourdieu, 1990b). In particular, field crossing highlighted how I conformed to the logic of the field and became an 'artifact' of the field to the extent that while I recognized and problematized many of the practices, I continued to invest in, and see the value of, 'playing the game' in the coaching field. Furthermore, there were advantages to being in a relation of belonging; money, travel, association with an international squad, bespoke kit, support for my coach development, and importantly - closeness and friendship with players and staff. These tensions are accentuated by the ethical implications of the unequal power relations between the athletes and I, both as a coach and as a non-disabled person. I was in a position in which I was able to control and 
influence the transmission and exchange of capital for the players, while at the same time placing the athletes as subjects of the research that I controlled (cf. Walmsley, 2004).

584 "secondary explanations" (Bourdieu, 1977: 20) for what I was observing and experiencing, my sense of unease with the methods and assumptions within the environment was ever-present and inhibiting of total investment. Indeed, field crossing prompted reflection upon the multiple and conflicting roles and responsibilities as a researcher, coach and critical voice in disability sport. My reluctance now to share these reflections is anchored in the dilemma of whether or not I risk alienating those whom I worked alongside.

\section{Implications and lessons learned}

591 The rigour of any ethnographic work rests firmly upon the researcher's awareness of what it is, and what is not, possible to say (Ball, 1990). In this paper we have discussed how through the use of epistemic reflexivity - enacted through the practice of 'crossing fields' - researchers can

594 make sense of, and perhaps challenge, that which 'goes without saying' in stratified sites of ethnographic inquiry. Importantly, "objectifying one's own universe" (Wacquant, 1989: 33) does not come 'naturally' (Lynch, 2000). As Bourdieu (1990a) argued, aspects of habitus owe

597 their specific efficacy to the fact that they are not easily accessible, which explains why 598 reflexive analyses tend to be "circumstantial and contingent" (Lynch, 2000: 36) on the 599 researcher's social location. It is therefore important to analyze the relationship between the 600 researcher, their object of study, and the broader field conditions in which both are situated 601 (Maton, 2003). Field crossing creates the conditions for an ongoing dialogue with theory, 602 reflection on the genesis and consequences of one's actions, and close scrutiny of our research

603 practices, which are seldom disclosed yet crucial in establishing transparency in the production 604 of research. 
606 providing insight into patterns of interaction, complexity and social context. Increased critical

607 scrutiny on the impacts of situating disabilities within high-performance coaching cultures is

608 particularly valuable for understanding disability sport as a site for resisting and reproducing

609 disability. However, these reflections on conducting research in disability sport coaching

610 should be seen not as confessions or 'hand-wringing' (Pillow, 2003; Gibson and Atkinson,

611 2018), but an attempt to decentre the analyst in relation to the field itself. The 'method' of

612 crossing fields highlighted how a socially instituted position as a researcher placed "outside of

613 the urgency of a practical situation" (Bourdieu, 1990b: 381) enabled critical reflection on the

614 hidden mechanisms and ideologies functioning within the coaching process that appeared

615 commonsense and natural.

616 For ethnographers, this research prompts critical questions on the extent to which

617 researchers can succumb to the practices and belief systems of a field, and how we can

618 reconstruct our research practices to provide useful challenge and critique. For social scientists,

619 ethnographic accounts that take a reflexive position are therefore better placed to problematise

620 the seemingly productive or unquestioned aspects of social life and how they intersect with

621 macro-structures such as - in this case - disability. In presenting this reflexive analysis, we

622 hope to provide a frame of reference to better understand the process of 'doing' ethnographic

623 research in socially significant yet contested social fields. To produce better research, we

624 encourage a reflexive gaze that recognizes and focuses attention on the ways that researchers

625 are situated across multiple intersecting fields, locating the foundations for knowledge

626 production and methodological rigour in networks of power and ideology, as a means for the

627 possibility of liberation from them.

628 References 
646

647

648

649

650

651

652

653

Adkins, L. (2003). Reflexivity: Freedom or Habit of Gender? Theory, Culture \& Society, 20(6), 21-42.

Alvesson M and Skoldberg K (2009) Reflexive Methodology: New Vistas for Qualitative Research. (2 ${ }^{\text {nd }}$ Ed.), London: Sage Publications.

Atkinson M \& Gibson K (2017) Power and Power Relations. In: Silk ML Andrews DL and Thorpe H (eds) Routledge Handbook of Physical Cultural Studies. London: Routledge, pp. $59-67$

Aune, J.A. (2011). The Scholastic Fallacy, Habitus, and Symbolic Violence: Pierre Bourdieu and the Prospects of Ideology Criticism. Western Journal of Communication, 75(4), 429433.

Author A and B (2015) Details withheld for peer review.

Authors A, B and others (2018) Details withheld for peer review.

Ball SJ (1990) Self-doubt and soft data: social and technical trajectories in ethnographic fieldwork. International Journal of Qualitative Studies in Education, 3(2): 157-171,

Berger, R. (2015). Now I see it, now I don't: researcher's position and reflexivity in qualitative research. Qualitative Research. 15(2): 219-234.

Berger, R.J. (2008). Disability and the Dedicated Wheelchair Athlete: Beyond the "Supercrip" Critique. Journal of Contemporary Ethnography. 37 (6): 647-678.

Blackett AD, Evans A and Piggott D (2015) Why 'the best way of learning to coach the game is playing the game': conceptualising 'fast-tracked' high-performance coaching pathways. Sport, Education and Society 22(6): 744-758.

Bourdieu P (1977) Outline of a theory of practice. Cambridge: Cambridge University Press.

Bourdieu P (1984) Distinction. London: Routledge and Kegan Paul.

Bourdieu P (1986) The forms of capital. In: Richardson (Ed) Handbook of theory and research for the sociology of education. New York: Greenwood, pp. 241-258.

Bourdieu P (1988) Homo Academicus. Cambridge: Polity Press

Bourdieu P (1989) Social Space and Symbolic Power. Sociological Theory, 7(1): 14-25.

Bourdieu P (1990a) The logic of practice. Cambridge: Polity Press.

Bourdieu P (1990b) The Scholastic Point of View. Cultural Anthropology 5(4), 380-391.

Bourdieu P (1996) Masculine Domination Revisited. Berkeley Journal of Sociology 41 : 189203. 
663

664

665

666

667

668

669

670

671

672

673

674

675

676

677

678

679

680

681

682

683

684

685

686

687

688

689

690

691

692

693

694

695

696

Bourdieu P and Wacquant LJD (1992) An invitation to reflexive sociology. Cambridge: Polity Press.

Campbell FK (2009) Contours of Ableism: The Production of Disability and Abledness. London: Palgrave Macmillan.

Clifford J \& Marcus G (Eds.) (1986) Writing culture: The poetics and politics of ethnography. Berkeley, CA: University of California Press

Denzin NK \& Lincoln YS [eds.] (2011) Sage Handbook of Qualitative Research, [4 $4^{\text {th }}$ ed.] Thousand Oaks, CA: Sage.

Foley DE (2002) Critical ethnography: The reflexive turn. International Journal of Qualitative Studies in Education. 15(4): 469-490.

Geertz C (1987). Works and lives: The anthropologist as author. Stanford: Stanford University Press.

Gibson K and Atkinson M (2018) Beyond Boundaries: The Development and Potential of Ethnography in the Study of Sport and Physical Culture. Cultural Studies $\leftrightarrow$ Critical Methodologies 18(6): 442-452

Guillemin M, and Gillam L. (2004) Ethics, reflexivity, and "ethically important moments" in research. Qualitative Inquiry, 10(1): 261-280.

Hammersley M and Atkinson P (2007) Ethnography: Principles in practice. $\left[3^{\text {rd }}\right.$ ed.] Abingdon: Routledge.

Howe P D (2009). Reflexive ethnography, impairment and the pub. Leisure Studies, 28(4): 489-496.

Kaiser K (2009) Protecting Respondent Confidentiality in Qualitative Research. Qualitative Health Research. 19(11): 1632-1641.

Lareau A and Weininger E (2003) Cultural capital in educational research: A critical assessment. Theory and Society 32(5-6): 567-606.

Lynch M (2000) Against reflexivity as an academic virtue and source of privileged knowledge. Theory, Culture and Society 17(3): 26-54.

Maton K (2003) Reflexivity, relationism, \& research: Pierre Bourdieu and the epistemic conditions of social scientific knowledge. Space and Culture 6(1): 52-65.

McNay L (1999) Gender, habitus and the field: Pierre Bourdieu and the limits of reflexivity. Theory, Culture \& Society 16(1): 95-117.

Olive R and Thorpe H (2011) Negotiating the 'F-Word' in the Field: Doing Feminist Ethnography in Action Sport Cultures. Sociology of Sport Journal 28(4): 421-440. 
Oliver M (1992) Changing the social relations of research production? Disability, Handicap and Society 7(2): 101-104.

Pillow W (2003) Confession, catharsis or cure? Rethinking the uses of reflexivity as methodological power in qualitative research. Qualitative Studies in Education 16(2): 175196.

Powis B (2018) 'We are playing for England, we wear the same shirt; just because I have a disability, it doesn't make me any different': empowerment, eliteness and visually impaired cricket. European Journal for Sport and Society, 15(2): 189-206.

Pringle R and Thorpe H (2017) Theory and reflexivity. In: Silk ML, Andrews DL and Thorpe H (eds.) Routledge Handbook of Physical Cultural Studies. London: Routledge, pp. 68-78.

Sparkes AC (2020) Autoethnography: accept, revise, reject? An evaluative self reflects. Qualitative Research in Sport, Exercise and Health. 12(2): 289-302.

Thomas C (2007) Sociologies of disability and illness. London: Palgrave.

Thorpe H (2009) Bourdieu, Feminism and Female Physical Culture: Gender Reflexivity and the Habitus-Field Complex. Sociology of Sport Journal 26(4): 491-516.

Thorpe H, Barbour K and Bruce T (2011) 'Wandering and wondering': theory and representation in feminist physical cultural studies. Sociology of Sport Journal 28(1): 106134.

Van Maanen J (1988) Tales of the Field: On Writing Ethnography. Chicago: University of Chicago Press.

Wacquant LJD (1989) Towards a reflexive sociology. A workshop with Pierre Bourdieu. Sociological Theory 7(1): 26- 63.

Wacquant LJD (2004) Following Pierre Bourdieu into the field. Ethnography Vol 5(4): 387414

Walmsley, J. (2004). Inclusive learning disability research: the (nondisabled)researcher's role. British Journal of Learning Disabilities. 32(1) 65-71. 